\title{
Microcirculatory function and left ventricular recovery after STEMI, exploring the hidden territories
}

\author{
P. Knaapen • N. van Royen
}

Published online: 29 March 2013

(C) The Author(s) 2013. This article is published with open access at Springerlink.com

In this issue, Remmelink and colleagues present very interesting data on the function of the coronary microcirculation after PCI-treated ST-segment elevation myocardial infarction (STEMI) [1].

The virtues of direct mechanical coronary revascularisation after acute thrombotic occlusion are well documented. Mortality after acute myocardial infarction has steeply declined over the past decades and is now well below $10 \%$ [2]. This is at least in part attributable to instant restoration of epicardial flow by stent placement, which puts primary PCI on a relatively short list of medical interventions that are directly lifesaving and also preserve quality of life.

As cardiologists we regularly witness such benefits of primary PCI. As an example, an amateur tennis player was brought into our cathlab recently with a large anterior myocardial infarction. He was haemodynamically unstable and in severe distress. After a quick and successful PCI procedure, he recovered fully and actually asked the medical staff whether he could return back to the court that same day because he was on the brink of winning his game (which was naturally denied...). Such exemplary stories have led some of us to believe that there is not much left to gain in the initial treatment strategy of AMI.

But the truth is of course a little different. Despite the approximate $95 \%$ angiographic success rate (TIMI-3 flow), the majority of patients will be left with scarred myocardium, exposing them to increased risk to develop heart failure. Especially the patients who show microvascular obstruction (MVO) at cardiac magnetic resonance (CMR) are prone to proceed to left ventricular dysfunction and its associated complications [3]. The exact pathophysiological substrate

P. Knaapen · N. van Royen $(\bowtie)$

Department of Cardiology, VU University Medical Centre,

De Boelelaan 1117,

$1081 \mathrm{HZ}$ Amsterdam, the Netherlands

e-mail: n.vanroyen@vumc.nl of this CMR-defined phenomenon remains unclear but it is associated with reduced or absent myocardial tissue perfusion and therefore sometimes also referred to as 'no reflow'.

This notion has opened a new potential therapeutic window since if we could identify the patients that are at risk early, we could also think of early adjunctive therapies after primary PCI.

In this light, studies as performed by Remmelink are of great importance.

The availability of intracoronary pressure and flow wires enables the quantification of microvascular function at different time points. Using such techniques, this group previously showed a direct relation between left ventricular recovery and coronary flow velocity reserve, as measured either directly or in the first week after AMI $[4,5]$. Conductance catheters can give insights into LV performance under different haemodynamic conditions. This has been employed especially in the pre-clinical setting, and provided us with very important insights on the autoregulatory way the heart responds to increased load as described in the Frank-Starling law.

Combining the two above-mentioned techniques, the authors show in their present study that patients with an impaired left ventricular arterial coupling, as determined by the ratio of ventricular end-systolic elastance to effective arterial elastance, display a decreased coronary flow velocity reserve. Interestingly, this was not related to a decreased maximal flow velocity rate during hyperaemia, which could be postulated after a large myocardial infarction and subsequent loss of microcirculatory capacity. Rather, it was related to an increased flow velocity rate at baseline. Resting flow is governed by vasomotor autoregulation and tightly matched to oxidative metabolism, which in turn is related to its main determinants such as end-systolic wall stress, contractility, and heart rate [6]. It is of interest to note that the patient group with a more pronounced compromised cardiac 
function also displayed a markedly higher heart rate. The increased coronary flow at rest may therefore reflect higher demand dictated by the haemodynamic status. Alternatively, impaired myocardial energetics and reduced cardiac efficiency could also have induced the apparent mismatch between resting perfusion and cardiac work [7].

Another aspect that we should keep in mind is the fact that the Doppler flow wire does not measure absolute flow but rather flow velocity. Thus, potentially it is only an increase in flow velocity that was observed, for example due to a different capacity of the vascular bed. To further differentiate between the potential mechanisms it would therefore be of interest to measure absolute myocardial perfusion in $\mathrm{ml} / \mathrm{min} / \mathrm{g}$ with techniques such as PET and MRI [8].

Using such quantitative perfusion imaging techniques in combination with invasive pressure measurements, Marques et al. studied coronary microvascular resistance in patients with a varying degree of LV dysfunction in the setting of a chronic myocardial infarction [9]. In that study, solely focusing on the residual viable tissue adjacent to scar rather than the complete infarct-related vascular territory, resting microvascular resistance was found to be increased. In contrast, minimal microvascular resistance was not compromised, similar to the findings of Remmelink et al. In the future, the further integration of invasive and non-invasive techniques to measure myocardial flow and microvascular resistance will probably give us more insights on the pathophysiological substrate of left ventricular dysfunction after successful primary PCI.

The authors are to be lauded for their very elaborate study, incorporating several physiological parameters that are only seldom measured in the clinical setting, which is dominated by large-scale pharmaco-interventional studies, focussing at hard endpoints. Such large-scale studies are of great importance to decide whether or not new therapies and interventions are to be implemented in daily clinical practice and they form the basis for evidence-based and guideline-directed medicine. The offspring of true innovation, however, most often lies in small-scale studies and the study by Remmelink is a nice example.

Funding None.

Conflict of interest None declared.

Open Access This article is distributed under the terms of the Creative Commons Attribution License which permits any use, distribution, and reproduction in any medium, provided the original author(s) and the source are credited.

\section{References}

1. Remmelink M, Sjauw KD, Yong ZY, et al. Coronary microcirculatory dysfunction is associated with left ventricular dysfunction during follow-up after STEMI. Neth Heart J. 2013. doi:10.007/ s12471-013-0382-2.

2. Fox KA, Steg PG, Eagle KA, et al. Decline in rates of death and heart failure in acute coronary syndromes, 1999-2006. JAMA. 2007;297(17):1892-900.

3. Wu KC, Zerhouni EA, Judd RM, et al. Prognostic significance of microvascular obstruction by magnetic resonance imaging in patients with acute myocardial infarction. Circulation. 1998;97(8):765-72.

4. Bax M, de Winter RJ, Schotborgh CE, et al. Short- and long-term recovery of left ventricular function predicted at the time of primary percutaneous coronary intervention in anterior myocardial infarction. J Am Coll Cardiol. 2004;43(4):534-41.

5. Hirsch A, Nijveldt R, Haeck JD, et al. Relation between the assessment of microvascular injury by cardiovascular magnetic resonance and coronary Doppler flow velocity measurements in patients with acute anterior wall myocardial infarction. J Am Coll Cardiol. 2008;51(23):2230-8.

6. Braunwald E. Control of myocardial oxygen consumption: physiologic and clinical considerations. Am J Cardiol. 1971;27(4):416-32.

7. Neubauer S. The failing heart — an engine out of fuel. N Engl J Med. 2007;356(11):1140-51.

8. Knaapen P, Camici PG, Marques KM, et al. Coronary microvascular resistance: methods for its quantification in humans. Basic Res Cardiol. 2009; 104(5):485-98.

9. Marques KM, Knaapen P, Boellaard R, et al. Hyperaemic microvascular resistance is not increased in viable myocardium after chronic myocardial infarction. Eur Heart J. 2007;28(19):2320-5. 